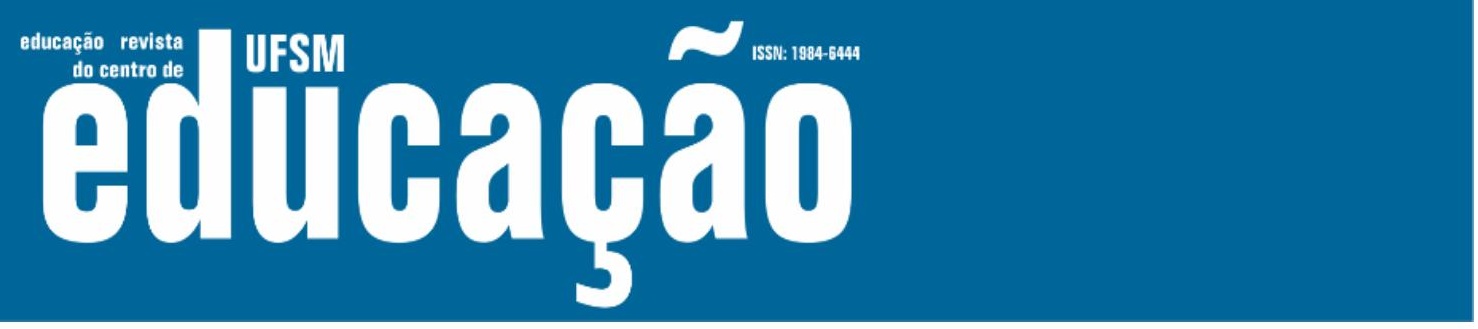

ISSN: 1984-6444 | http://dx.doi.org/10.5902/1984644443325

\title{
Base Nacional Comum Curricular de Educação Física: tensionamentos e demarcações ${ }^{1}$
}

\author{
Base Nacional Comum Curricular of Physical Education: tensions and \\ demarcations
}

\author{
Alexandre Paulo Loro \\ Professor Adjunto da Universidade Federal da Fronteira Sul. Chapecó, Santa Catarina, Brasil. \\ alexandre.loro@uffs.edu.br - https://orcid.org/0000-0002-4207-7642 \\ Meire Aparecida Lóde Nunes \\ Professor Adjunto da Universidade Estadual do Paraná. Paranavaí, Paraná, Brasil. \\ meirelode@gmail.com - https://orcid.org/0000-0002-2031-9743
}

Recebido em 03 de abril de 2020

Aprovado em 29 de agosto de 2020

Publicado em 30 de setembro de 2021

\section{RESUMO}

A Base Nacional Comum Curricular de Educação Física (BNCC-EF) tem provocado a formulação de inúmeras críticas por parte dos profissionais da área. O objetivo central deste ensaio consiste em identificar os discursos que permeiam o campo da Educação Física, os quais pretendem obter legitimidade por meio da sua inserção no mencionado documento. A Análise do Discurso (AD) foucaultiano foi a ferramenta teórico-metodológica utilizada, com a intenção de compreender as formas pelas quais diferentes agentes ligam-se a determinados discursos, na tentativa de produzir efeitos de verdade. A política educacional em curso no Brasil colocou em prática um projeto de poder, com vistas a inculcar e consolidar determinado discurso-prática (habilidades e competências), o que transparece na estruturação do documento. Diante do jogo de forças existentes, avaliamos que a BNCC-EF não gerou apenas uma crise capaz de catalisar a corrente crítica, mas colocou em evidência um campo que ainda permanece em constante disputa.

Palavras-chave: Currículo; Educação Física; Discursos.

\section{ABSTRACT}

The Base Nacional Comum Curricular of Physical Education caused the formulation of innumerable criticisms by professionals in this area. The main objective of this essay consists in identify the discourses that permeate the field of Physical Education, which intend to obtain legitimacy through their insertion in the mentioned document. Foucault's Discourse Analysis was the theoretical-methodological tool used, with the intention of understand the ways in which different agents are linked to certain 


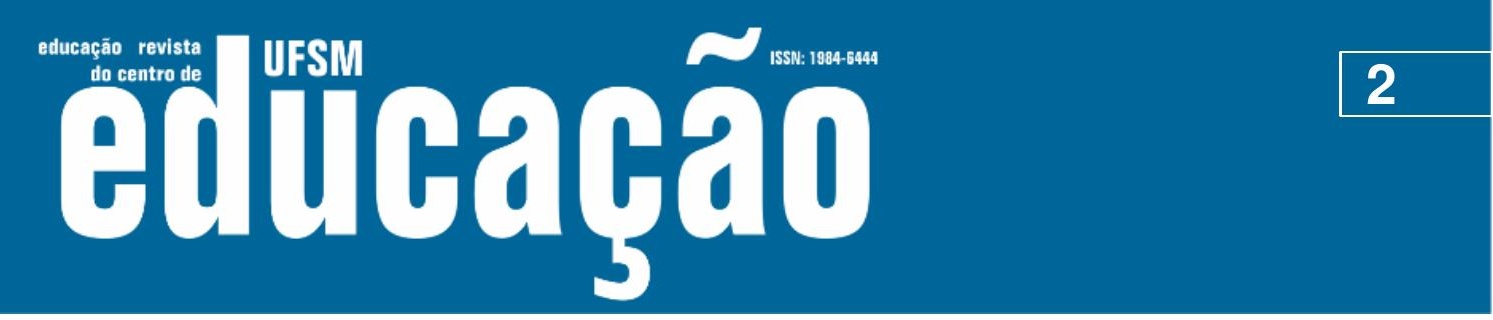

ISSN: 1984-6444 | http://dx.doi.org/10.5902/1984644443325

speeches, in an attempt to produce real effects. The educational policy in progress in Brazil put in place a power project, aiming to inculcate and consolidate a certain discourse-practice (skills and competences), what appears in the extructuring of the document. Considering the existence of a game of forces, we believe that Base Nacional Comum Curricular of Physical Education not only generated a crisis capable of catalyzing the critical current, but also highlighted a field that still remains in constant dispute.

Keywords: Curriculum; Physical Education; Speeches.

\section{Introdução}

A Base Nacional Comum Curricular (BNCC) é um documento normativo que define um conjunto de aprendizagens essenciais que todos os alunos têm direito na Educação Básica, perspectivando colocar a educação brasileira em compasso com as demandas do século XXI. Cabe, portanto, algumas problematizações: quem define o que é essencial? Que educação queremos para o século XXI?

A BNCC foi elaborada coletivamente durante anos, sendo a publicação final aguardada por diferentes agentes da educação. Entretanto, desde a elaboração das primeiras versões (I-II), posteriormente disponibilizadas em 2015 e 2016, respectivamente, a BNCC demonstrou ser um território de divergências. $A$ falta de consenso, aliada a permanente contestação política do documento, provocaram constantes tensionamentos, os quais perduraram durante a fase de elaboração da última versão (III), sendo disponibilizada a versão final em 2017.

Ao seguir uma determinada lógica organizacional, o documento está alicerçado em competências e habilidades esperadas, as quais serão desenvolvidas a partir dos conteúdos de todas as áreas do conhecimento. Essa estruturação tem gerado confrontos e resistências no interior das políticas educacionais e curriculares no contexto atual, especialmente por estar em fase de implementação. Ainda persistem as críticas de instituições e pesquisadores, os quais se manifestaram contrários ao teor do documento, apontando superficialidades, omissões ou mesmo proposições desejadas. Esses posicionamentos críticos estão fundamentados em diferentes 


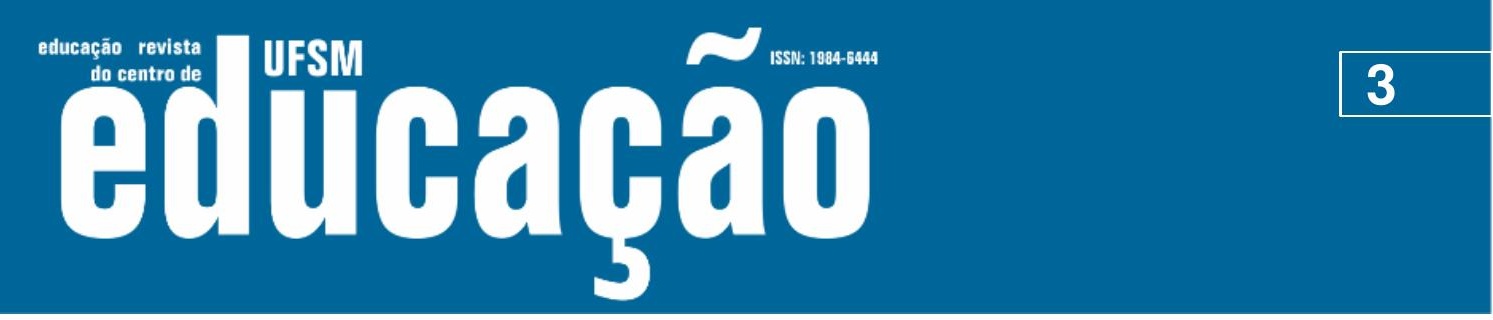

ISSN: 1984-6444 | http://dx.doi.org/10.5902/1984644443325

visões de mundo e podem ser compreendidos a partir dos desdobramentos da constituição do próprio campo acadêmico, com vistas a atender diferentes finalidades.

Ao analisar especificamente a área de Educação Física, tal constatação nos conduziu à estruturação do seguinte problema de pesquisa: de que modo as críticas à Base Nacional Comum Curricular de Educação Física (BNCC-EF) evidenciam disputas do campo acadêmico?

Ao constatar o jogo de forças existente nas disputas teóricas, que se desdobram em políticas públicas, temos como objetivo central deste ensaio identificar os discursos que permeiam o campo da Educação Física, os quais pretendem obter legitimidade por meio da sua inserção no mencionado documento. Para tanto, dialogamos com a literatura da área de Educação Física para a análise de pontos de tensão em torno do documento.

A Análise do Discurso $(A D)$ foucaultiano foi a ferramenta teórico-metodológica utilizada, com a intenção de compreender as formas pelas quais diferentes agentes ligam-se a determinados discursos na tentativa de produzir efeitos de verdade. A noção de discurso é empregada nesse artigo como "[...] um conjunto de regras anônimas, históricas sempre determinadas no tempo espaço, que definiram em uma dada época, e para uma área social, econômica, geográfica, ou linguística dada, as condições de exercício da função enunciativa" (FOUCAULT, 2008, p. 133).

O ensaio foi organizado em três seções interdependentes: 1) o percurso que delineou a proposta da BNCC e as relações intrínsecas à Educação Física; 2) discussão e análise de diferentes projetos em disputa em seu campo teórico; 3) e na terceira e última seção, teceremos as considerações finais.

\section{A Base Nacional Comum Curricular}

O debate que permeou a elaboração da BNCC não é recente, embora aparente ser, uma vez que consta desde a Constituição (1988) a ênfase para a educação a serviço do pleno desenvolvimento da pessoa, preparo para o exercício da cidadania e a qualificação para o trabalho. Destaca-se na Carta Magna o Artigo 210, ao determinar que "Serão fixados conteúdos mínimos para o ensino fundamental, de 


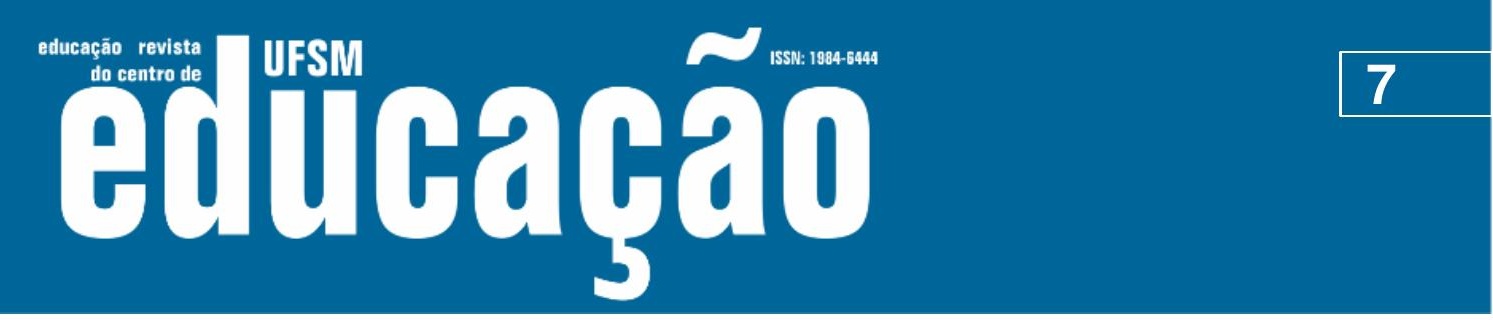

ISSN: 1984-6444 | http://dx.doi.org/10.5902/1984644443325

o Ensino Fundamental (junto com Língua Portuguesa, Artes e Língua estrangeira inglesa), a Educação Física visa assegurar aos alunos o desenvolvimento de dez (10) competências específicas:

1. Compreender a origem da cultura corporal de movimento e seus vínculos com a organização da vida coletiva e individual.

2. Planejar e empregar estratégias para resolver desafios e aumentar as possibilidades de aprendizagem das práticas corporais, além de se envolver no processo de ampliação do acervo cultural nesse campo.

3. Refletir, criticamente, sobre as relações entre a realização das práticas corporais e os processos de saúde/doença, inclusive no contexto das atividades laborais.

4. Identificar a multiplicidade de padrões de desempenho, saúde, beleza e estética corporal, analisando, criticamente, os modelos disseminados na mídia e discutir posturas consumistas e preconceituosas.

5. Identificar as formas de produção dos preconceitos, compreender seus efeitos e combater posicionamentos discriminatórios em relação às práticas corporais e aos seus participantes.

6. Interpretar e recriar os valores, os sentidos e os significados atribuídos às diferentes práticas corporais, bem como aos sujeitos que delas participam.

7. Reconhecer as práticas corporais como elementos constitutivos da identidade cultural dos povos e grupos.

8. Usufruir das práticas corporais de forma autônoma para potencializar o envolvimento em contextos de lazer, ampliar as redes de sociabilidade e a promoção da saúde.

9. Reconhecer o acesso às práticas corporais como direito do cidadão, propondo e produzindo alternativas para sua realização no contexto comunitário.

10. Experimentar, desfrutar, apreciar e criar diferentes brincadeiras, jogos, danças, ginásticas, esportes, lutas e práticas corporais de aventura, valorizando o trabalho coletivo e o protagonismo (BRASIL, 2018, p. 223).

As competências específicas almejam proporcionar aprendizagens corporais no interior da escola bem como a sua transposição para outros momentos do cotidiano, enfocando o respeito à cultura (ao incorporar concepções assentadas no paradigma cultural da Educação Física) e a importância que determinadas práticas corporais têm em suas origens para os indivíduos, em uma abordagem alicerçada em três elementos fundamentais comuns: "[...] movimento corporal como elemento essencial; organização interna (de maior ou menor grau), pautada por uma lógica específica; e produto cultural vinculado com o lazer/entretenimento e/ ou o cuidado com o corpo e a saúde" (BRASIL, 2018, p. 213). 


\section{Aillbapẫ

ISSN: 1984-6444 | http://dx.doi.org/10.5902/1984644443325

A versão final da BNCC-EF não teve muitas preocupações com a contribuição de especialistas, ou mesmo com subsídios oriundos dos debates e desdobramentos que ocorreram no interior da academia, inclusive fica evidente que parte das discussões suscitadas nos documentos preliminares da BNCC (I-II) foram suprimidas. Nos termos em que foi configurada a BNCC, ficou enxuta quando comparada às versões anteriores. Pragmática e com padronização genérica, lembra um manual técnico. Ao indicar parâmetros gerais, estabelece uma espécie "métrica" em larga escala.

$\mathrm{Na}$ análise de Moreira et al. (2016, p. 73) o manuscrito preliminar das BNCC apresentava ecletismo, no que diz respeito à concepção de Educação Física, quer dizer, que "[...] não demonstra clareza quanto à defesa histórica deste componente curricular na educação básica e nem se alinha à reivindicação desta como um campo de conhecimento multidisciplinar e de intervenção pedagógica [...]". A versão final da BNCC apresenta a promessa de permitir ao professor e a escola fazer escolhas, sem engessar os processos. Contudo, ainda pairam contradições e/ou inconsistências da BNCC, as quais podem ser interpretadas como falta de consenso da área quanto às atribuições ou ao escopo de conhecimentos da Educação Física.

A elaboração de uma base nacional em um país diversificado é uma proposição necessária e desafiadora, inclusive para a área de Educação Física, embora não tenhamos muitas certezas de melhoria. Ainda assim, estamos diante de uma oportunidade histórica, fundamentalmente porque é imprescindível a inserção da Educação Física no documento. Como pensar a base sem a Educação Física? Ademais, é preciso reconhecer que a BNCC-EF apresenta direções, mesmo precisando de permanente revisão.

\section{Educação Física: um campo em permanente disputa discursiva}

A Educação Física, enquanto Componente Curricular obrigatório, passou por um processo de transformação nas últimas décadas. Para González e Fensterseifer (2009), o movimento renovador da Educação Física brasileira (década de 1980), ao questionar o paradigma de aptidão física e esportiva que sustentava de forma 


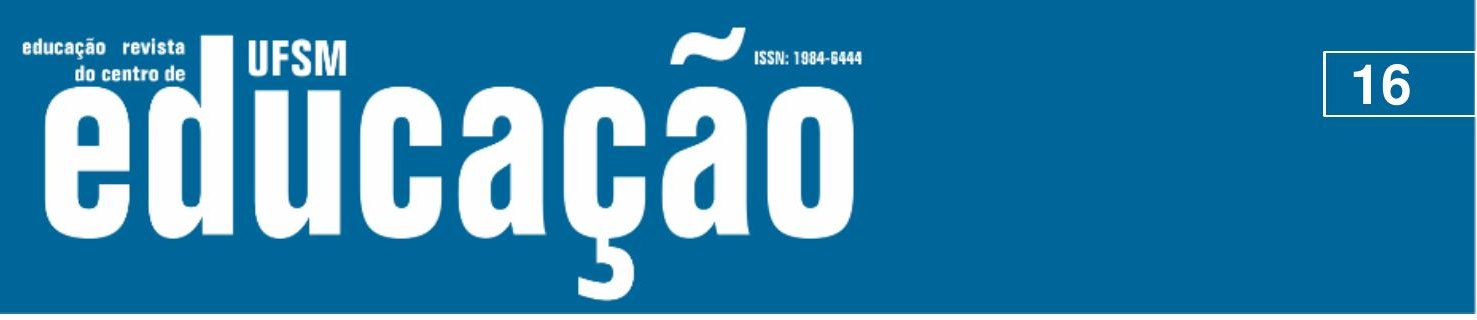

ISSN: 1984-6444 | http://dx.doi.org/10.5902/1984644443325

\begin{abstract}
Na verdade, tais constrangimentos, visíveis sobretudo na aprovação da Base Nacional Comum Curricular (BNCC), permitem algumas reflexões acerca do que está em jogo nesse processo. Com o pretexto de melhorar os resultados pífios da educação nacional, a BNCC foi proposta como uma política de Estado que pretendia, apenas, concretizar alguns objetivos que já constavam da legislação do país. O processo de resistência, iniciado pelos que discordam da existência de um currículo nacional no País, bem como o jogo político manifesto nesse percurso, corroboram a ideia de que o documento acabará por gerar distintos constrangimentos ao nível da comunidade escolar e científica (CORRÊA; MORGADO, 2018, p. 02).
\end{abstract}

Os referidos autores, alicerçados na abordagem do "ciclo de políticas" 5 , proposto originalmente por Ball (1994), destacam que a elaboração da BNCC contou com diferentes atores e que, portanto, se faz necessário desvelar de que forma os interesses e a ideologia, fruto de acordos e de disputas, foram sendo sistematizados. Nesse sentido, diferentes discursos são evidenciados, como o discurso pedagógico. Este conjunto de regras e mecanismos de poder é representado no processo político à medida que novos elos de poder e influência são construídos e fortalecidos, constituindo um ciclo de políticas públicas. Não se pode perder de vista que, além da Comissão instituída pelo MEC e representantes de universidades, também foram estabelecidas "parcerias" com grupos de entidades privadas, dentre eles, o Movimento pela Base Nacional Comum (MBNC), que representa os interesses de empresas, fundações e instituições filantrópicas, financiadas pela alocação de impostos de grandes corporações. O grupo que elaborou o texto é constituído por "[...] uma comunidade de discursos focada na necessidade de reforma educacional, composta por empreendedores políticos, tecnocratas viajantes e 'líderes de pensamento', como soluções para os 'problemas' da política educacional” (p. 06-07).

A análise internacional da BNCC por entidades privadas tende a desvalorizar/deteriorar a imagem do público e, em contrapartida, "exaltar as bondades do privado" (MORGADO, 2003), minimizando o papel do Estado. Esse processo emite um discurso falacioso, criando o mito político eficiente que celebra a "superioridade" da gestão do setor privado em "parceria" com o Estado, sobre/contra a modalidade conservadora e burocrática de administração do setor público. Essa suposta superioridade geralmente está fundamentada nas experiências e referências internacionais de grupos privados de educação, produzindo a falsa ideia de 


\section{Aillbapẫ \\ 3}

ISSN: 1984-6444 | http://dx.doi.org/10.5902/1984644443325

\section{Considerações finais}

Ao considerar o jogo de forças que permearam o campo da Educação Física e continuaram a se refletir na construção da BNCC, compreendemos que o não dito é maior. A política educacional em curso no Brasil colocou em prática um projeto de poder, com vistas a inculcar e consolidar determinado discurso-prática (habilidades e competências), o que transparece na estruturação do documento. Diante do jogo de forças existentes, avaliamos que a BNCC-EF não gerou apenas uma crise capaz de catalisar a corrente crítica, mas colocou em evidência um campo que ainda permanece em constante disputa.

Isto quer dizer que teremos muitos desafios pela frente. Um deles será a preparação das instituições e professores para a operacionalização da BNCC-EF. Como será a aceitação, a compreensão e possível implementação dos pontos previstos da BNCC-EF nas escolas é uma pergunta pertinente. É provável que as instituições e os professores reelaborem e ressignifiquem os dispositivos normativos a partir das condições reais que o meio oferece, segundo suas perspectivas e culturas, afinal sempre haverá a necessidade de reanálise e reinterpretação para ocorrer apropriação, uma vez que o alcance de qualquer reforma é limitado -, afinal, preceitos não são garantias de "obediência" ou mesmo "fidelidade".

Não acreditamos que uma proposta consensual de Base seria possível (uma vez que estamos analisando o problema de uma perspectiva discursiva). Da mesma forma, a inexistência de consenso sobre o documento é algo indesejável. Parafraseando Betti (2017), ao referir-se a BNCC-EF: "ruim com ela, pior sem ela". Ainda assim, parece-nos fundamental um conjunto maior de estudos sobre esse tema e continuar perguntando como estão sendo interpretados os confrontos e as resistências nesse documento.

\section{Referências}

BALL, Stephen J. Education reform: a critical and post structural approach. Buckingham: Open University Press, 1994. 


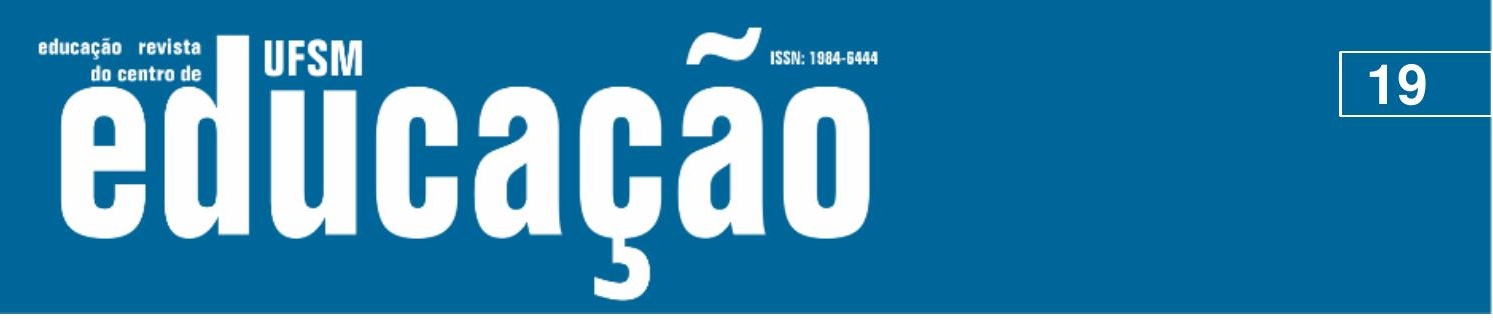

ISSN: 1984-6444 | http://dx.doi.org/10.5902/1984644443325

BETTI, Mauro. A versão final da Base Nacional Comum Curricular da Educação Física (Ensino Fundamental): menos virtudes, os mesmos defeitos. Revista Brasileira de Educação Física Escolar, Curitiba, v. 4, 2018, p. 156-175.

BETTI, Mauro. Base Nacional Comum Curricular (BNCC) de Educação Física do Ensino Fundamental: Ruim com Ela, Pior Sem Ela. Blog do Cev, 2017. Disponível em: http://cev.org.br/biblioteca/base-nacional-comum-curricular-bncc-de-educacaofisica-do-ensino-fundamental-ruim-com-ela-pior-sem-ela. Acesso em: 29 jul. 2019.

BRACHT, Valter. Educação física \& ciência: cenas de um casamento (in)feliz. 3. ed. ljuí: Unijuí, 2007.

BRASIL. Constituição da República Federativa do Brasil (1988). Brasília, DF: Senado Federal, 1988.

BRASIL. Lei no 9.394, de 20 de dezembro de 1996. Estabelece as diretrizes e bases da educação nacional. Diário Oficial da União: seção 1, Brasília, DF, $n^{\circ}$ 248, p. 27833-27841, 23 dez. 1996.

BRASIL. Ministério da Educação; Secretaria de Educação Básica; Secretaria de Educação Continuada, Alfabetização, Diversidade e Inclusão; Secretaria de Educação Profissional e Tecnológica. Conselho Nacional de Educação; Câmara de Educação Básica. Diretrizes Curriculares Nacionais da Educação Básica. Brasília: MEC; SEB; DICEI, 2013.

BRASIL. Lei n 13.005, de 25 de junho de 2014. Aprova o Plano Nacional de Educação - PNE e dá outras providências. Diário Oficial da União, Brasília, DF, 26 jun. 2014.

BRASIL. Ministério da Educação. Secretaria da Educação Básica. Base Nacional Comum Curricular. Brasília, DF, 2018. Disponível em: http://basenacionalcomum.mec.gov.br/. Acesso em: 04 jun. 2019.

BRASIL. Resolução n 4, de 17 de dezembro de 2018. Institui a Base Nacional Comum Curricular na Etapa do Ensino Médio (BNCC-EM), como etapa final da Educação Básica, nos termos do artigo 35 da LDB, completando o conjunto constituído pela BNCC da Educação Infantil e do Ensino Fundamental, com base na Resolução CNE/CP no 2/2017, fundamentada no Parecer CNE/CP n 15/2017. Diário Oficial da União: seção 1, Brasília, DF, no 242, p.120, 18 dez. 2018.

CORRÊA, Adriana Corrêa; MORGADO, José Carlos. A construção da Base Nacional Comum Curricular no Brasil: tensões e desafios. In: COLÓQUIO LUSO-BRASILEIRO DE EDUCAÇÃO (COLBEDUCA), 4., 2018, Braga e Paredes de Coura, Portugal. Anais [...] Braga e Paredes de Coura, Portugal: UDESC, UMinho e UFPA, 2005. p. 112. 


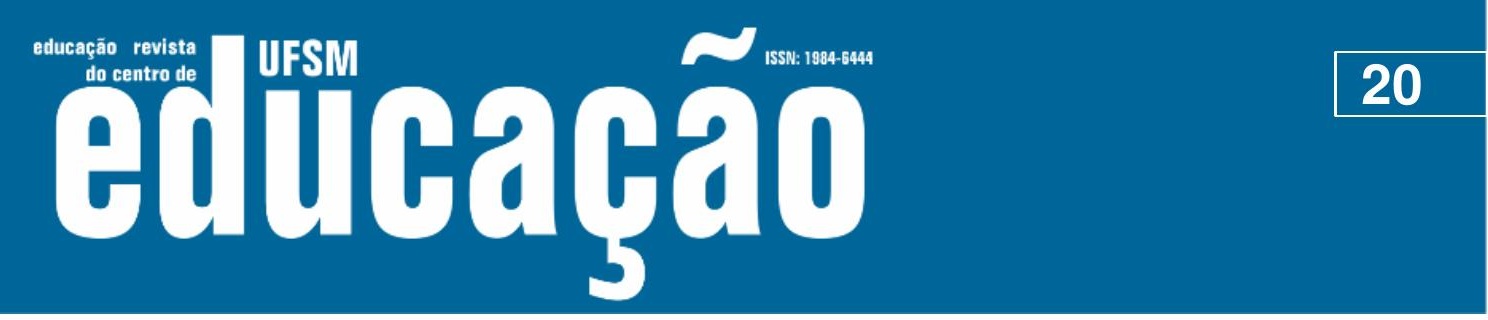

ISSN: 1984-6444 | http://dx.doi.org/10.5902/1984644443325

DESSBESELL, Giliane. Exercícios físicos na Base Nacional Comum Curricular: um fio solto na trama discursiva da cultura corporal de movimento. 2018. 154f. Tese (Doutorado em Educação Física) - Escola da Educação Física, Fisioterapia e Dança, Universidade Federal do Rio Grande do Sul, Porto Alegre, 2018.

DESSBESELL, Giliane; FRAGA, Alex Branco. Exercícios físicos na Base Nacional Comum Curricular: um estranho no nicho da cultura corporal de movimento. Movimento, Porto Alegre, p. 1-14, 2020.

FOUCAULT, Michel. A Arqueologia do Saber. 7 ed. Rio de Janeiro: Forense Universitária, 2008.

GONZÁLEZ, Fernando Jaime; FENSTERSEIFER, Paulo Evaldo. Entre o "não mais" e o "ainda não": pensando saídas do não-lugar da EF Escolar I. Cadernos de formação RBCE, Campinas, v. 1, n. 1, 2009, p. 9-24.

GONZÁLEZ, Fernando Jaime; FRAGA, Alex Branco. Afazeres da Educação Física na escola: planejar, ensinar, partilhar. Erechim: Edelbra, 2012.

MOREIRA, Laine Rocha et al. Apreciação da base comum curricular e a educação física em foco. Motrivivência, Florianópolis, v. 28, 2016, p. 61-75.

MORGADO, José Carlos. Processos e práticas de (re)construção da autonomia curricular. 2003. Tese (Doutorado em Educação). Instituto de Educação, Universidade do Minho, Braga, 2003.

NEIRA, Marcos Garcia. Incoerências e inconsistências da BNCC de Educação Física. Revista Brasileira de Ciências do Esporte, Porto Alegre, v. 40, n. 3, jul./set. 2018, p. 215-223.

This work is licensed under a Creative Commons Attribution-NonCommercial 4.0 International (CC BY-NC 4.0)

\section{Notas}

\footnotetext{
1 O presente trabalho foi realizado com o apoio da Coordenação de Aperfeiçoamento de Pessoal de Nível Superior (CAPES) - Código de Financiamento 001.

2 O Ministério da Educação também estabeleceu interlocução com as Associações Profissionais e Científicas, as quais contribuíram criticamente na discussão pública para a construção da Base Nacional Comum Curricular, dentre elas, o Colégio Brasileiro de Ciências do Esporte (CBCE).
} 


\section{Lew Ellibahá}

ISSN: 1984-6444 | http://dx.doi.org/10.5902/1984644443325

${ }^{3} \mathrm{O}$ autor participou ativamente nas discussões e proposições durante a elaboração da segunda versão da BNCC, sendo um dos membros especialistas do Ensino Fundamental (Anos Iniciais) para a área da Educação Física.

4 Para a realização da investigação a pesquisadora tomou como materialidade empírica os seguintes documentos: as três versões da BNCC, as contribuições oriundas da consulta pública, os relatórios dos seminários estaduais sobre a BNCC, os textos dos leitores críticos contratados pelo MEC e as propostas curriculares estaduais.

${ }^{5} \mathrm{O}$ ciclo de políticas proposto por Ball e colaboradores é um método para a pesquisa de políticas educacionais. O ciclo contínuo é constituído por cinco contextos: o contexto de influência, o contexto da produção do texto, o contexto da prática, o contexto dos resultados (efeitos) e o contexto da estratégia política (CORRÊA; MORGADO, 2018). 